\title{
The Foundations of Capability Theory: Comparing Nussbaum and Gewirth
}

\author{
Rutger Claassen • Marcus Düwell
}

Accepted: 19 March 2012 / Published online: 11 April 2012

C The Author(s) 2012. This article is published with open access at Springerlink.com

\begin{abstract}
This paper is written from a perspective that is sympathetic to the basic idea of the capability approach. Our aim is to compare Martha Nussbaum's capability theory of justice with Alan Gewirth's moral theory, on two points: the selection and the justification of a list of central capabilities. On both counts, we contend that Nussbaum's theory suffers from flaws that Gewirth's theory may help to remedy. First, we argue that her notion of a (dignified) human life cannot fulfill the role of a normative criterion that Nussbaum wants it to play in selecting capabilities for her list. Second, we question whether Nussbaum's method of justification is adequate, discussing both her earlier self-validating argumentative strategy and her more recent adherence to the device of an overlapping consensus. We conclude that both strategies fail to provide the capabilities theory with the firm foundation it requires. Next, we turn to Gewirth's normative theory and discuss how it can repair these flaws. We show how his theory starts from a fundamental moral principle according to which all agents have rights to the protection of the necessary preconditions of their agency. Gewirth's justification of this principle is then presented, using a version of a transcendental argument. Finally, we explicitly compare Nussbaum and Gewirth and briefly demonstrate what it would mean for Nussbaum to incorporate Gewirthian elements into her capabilities theory of justice.
\end{abstract}

Keywords Capability approach · Selection of capabilities · Justification of capabilities · Martha Nussbaum · Alan Gewirth

\section{Introduction}

In the last decade discussions about the capabilities approach have received a lot of attention. While in the beginning this approach was mainly focused on measuring equality and quality

R. Claassen $(\bowtie)$

Institute of Political Science, Leiden University, Wassenaarseweg 52, 2333 AK Leiden, The Netherlands e-mail: claassenrjg@fsw.leidenuniv.nl

M. Düwell

Department of Philosophy, Utrecht University, Janskerkhof 13a, room 1.12, 3512 BL Utrecht, The Netherlands e-mail: M.Duwell@uu.nl 
of life, more recently the approach is presented as a general framework for normative questions in ethics and political philosophy. Martha Nussbaum's version of the capabilities approach has contributed to this shift. However, there are several aspects of the approach which are quite underdeveloped, especially with respect to its ethical assumptions. Why does the protection of basic capabilities have normative force for us? Is this normativity in a moral sense, a political sense, or both? How do human capabilities relate to the human rights framework? What kind of justification does the capabilities approach offer for its claims?

In moral and political philosophy the capabilities approach is most often discussed in relation to (neo-)Aristotelian and contractualist theories, but discussions with (neo-)Kantian theories are missing in the literature. This is surprising since Nussbaum has come to link her theory more and more closely to Kantian concepts. For example, her reference to the concept of human dignity strengthens the links to the deontological tradition, even if she presents it as an Aristotelian concept of dignity (Nussbaum 2008). Also, one can wonder whether her concept of normativity can really be interpreted as Aristotelian. Doesn't it rather presuppose some idea of categorical obligations that can better be interpreted in a Kantian way? To develop the most promising justification for the protection of capabilities, we think it would be helpful to discuss the approach in comparison to theoretical alternatives from a more Kantian origin. In this paper, we will focus on the, in our eyes, most obvious candidate for such a comparison: her former colleague at the University of Chicago, Alan Gewirth.

The similarities between their theories seem stronger than with other prominent contemporary Kantians (like Barbara Herman, Thomas Hill, Christine Korsgaard, Onora O'Neill). Both Nussbaum and Gewirth want to spell out justice in terms of rights and connect this to human dignity; both want to justify universal moral obligations with regard to the protection of those rights; both extend the scope of rights beyond negative rights to include positive rights (to say it in political terms: both are more social-democratic than libertarian); both see normative duties as neither directed to the realization of specific goals nor to the maximization of goods or utility, but instead as moral obligations to protect and support the necessary preconditions of human life. These similarities are so strong that one can wonder why a comparison of both theories has not been published so far. ${ }^{1}$ Such a comparison will be all the more fruitful since there are also important differences between their theories. While Nussbaum sees capabilities as oriented towards different aspects of human life which cannot be hierarchically ranked, Gewirth wants to offer a hierarchy between different rights; Gewirth offers one supreme principle that justifies such a hierarchy, while Nussbaum does not; Nussbaum (at least more recently) justifies normative claims by reference to a Rawlsian 'overlapping consensus', while Gewirth offers a transcendental argument to justify his theory.

This paper is written from a perspective that is sympathetic to the basic idea of the capability approach. Nonetheless, we will be critical of many aspects of Nussbaum's theory and argue that it can profit from the more explicit discussions about meta-ethical and justificatory assumptions that we find in Gewirth and those authors defending his theory. It is worth considering whether Gewirth's strategy opens up theoretical perspectives that help overcome the shortcomings of the capabilities approach. Even for those unconvinced by Gewirth's theory, our comparison may have important insights to offer. It may help

\footnotetext{
${ }^{1}$ Some of this might be due to the fact that Gewirth has hardly been discussed in political philosophy, although there are many publications in (bio)ethics and law on his work. Nussbaum formulates some words of graditute towards Gewirth in Frontiers of Justice (Nussbaum 2006, p.viii) and wrote a comment for the cover of Gewirth's The Community of Rights (1996). This suggests that some discussions have probably taken place in Chicago, even though they did not find their way in academic publications.
} 
understand which theoretical questions would have to be answered in order to develop the capabilities approach into a convincing ethical and political approach. ${ }^{2}$

The first part of the paper contains a discussion of the major flaws in Nussbaum's capabilities approach as we conceive of them. First, we question the content of her capabilities list, asking whether the selection of capabilities for the list has proceeded in an adequate way. Here our criticism is that the notion of a (dignified) human life cannot fulfill the role of a normative criterion that Nussbaum wants it to play. It merely generates anthropological observations, not the needed moral or political entitlements and obligations that Nussbaum's theory aims to establish (Section 2). Second, we discuss whether Nussbaum's method of justification is adequate. Here we discuss both her earlier self-validating argumentative strategy and her more recent adherence to the device of an overlapping consensus. We conclude that both strategies fail to provide the capabilities theory with the firm foundation it requires (Section 3). Then, in the second part of the paper we present Gewirth's normative theory and discuss how it can remedy the flaws we identified in Nussbaum. First, we show how his theory starts from a fundamental moral principle according to which all agents have rights to the protection of the necessary preconditions of their agency (Section 4). Gewirth's justification of his principle is then presented, using a version of a transcendental argument (Section 5). Finally, we explicitly compare Nussbaum and Gewirth and briefly demonstrate what it would mean for Nussbaum to incorporate these Gewirthian elements into her capabilities theory of justice (Section 6).

\title{
2 The Selection of Capabilities
}

Any capability theorist who wants to defend a list of basic capabilities needs a normative criterion (or set of criteria) that guides the selection of these capabilities. Nussbaum has consistently defended a criterion that we will refer to as 'humanity' (alternatively: 'human nature' or 'human life'). This is shorthand for her idea that we seek the capabilities belonging to a life that is 'truly human'. The question in this section is: does this criterion succeed in doing what it is supposed to do, i.e. generate a list of political entitlements and obligations? $?^{3}$ Nussbaum herself explains that her list is an answer to the question:

\begin{abstract}
'What are the features of our common humanity, features that lead us to recognize certain others, however distant their location and their forms of life, as humans and, on the other hand, to decide that certain other beings who resemble us superficially could not possibly be human?' (Nussbaum 1990, p. 219).
\end{abstract}

\footnotetext{
${ }^{2}$ We only discuss Nussbaum's version of the capabilities approach (and not other versions, such as Amartya Sen's) for reasons of necessary limitations, but also because Nussbaum is relatively more explicit than others about the philosophical assumptions of her capabilities approach.

${ }^{3}$ One might object that in later works she has changed the criterion, because she now consistently speaks of dignity and 'a life worthy of that dignity' (Nussbaum 2006, p. 74; see also Nussbaum 2008). However, the role that the later Nussbaum assigns to dignity is not theoretically clearly developed, nor does she specify what the implications are of adopting this concept. It apparently does not change the selection of capabilities for the list, or at least she has never shown a new derivation of her central capabilities based on the notion of dignity. Instead, she gives the impression that the older derivation from the concept of human nature is still in full force. Nussbaum furthermore states: 'Dignity is not defined prior to and independently of the capabilities, but in a way intertwined with them and their definition' (Nussbaum 2006, p. 162). Similarly (Nussbaum 2006, p. 174). So far, dignity for Nussbaum seems a mere epiphenomenon with respect to the concept of the capabilities. If dignity has higher importance for the understanding of the capabilities approach, this importance has not been theoretically elaborated so far.
} 
Nussbaum develops her account of humanity through a reading of ancient Greek texts, both philosophical and literary. She maintains that the stories and myths that the Greeks used have the function of identifying the essentials of human nature. They do so by distinguishing humanness from the life of beasts on the one hand and the life of the gods on the other hand. Through a comparison with animal and godlike life, we come to see there are certain features that are unique to us as human beings. Aristotle also stands in this Greek tradition. For example, if we were gods we would lead a nonfinite life. This, Aristotle argues, would mean that virtues such as justice and moderation have no application to us. The fact that they do is part of what makes us human. Similarly, beasts lack reason and language. And where they are portrayed in myths as speaking and thinking, they lack other characteristics, such as the Cyclopes' lack of respect for the convention of hosting strangers (Nussbaum 1995, pp. 95-97).

Nussbaum then uses this basic argumentative strategy to provide a more systematic account of what it is to be human. For example, she argues that all human beings face death and that they generally all want to live. If we would encounter anthropomorphic creatures that have eternal life, or on the other hand, that do not attach value to their lives but want to die as quickly as possible, we would consider them to be so different from ourselves that we would not qualify them as human. Hence there is reason to include the basic capability of life on the list (Nussbaum 1990, p. 219). Similar arguments are made about the other nine capabilities. For instance, Nussbaum argues that human beings are such that they are also dependent on non-human nature. Moreover, we would not recognize as human a creature that 'treated animals exactly like stones' (Nussbaum 1990, p. 222). Hence she concludes that we should have a capability to relate in an appropriate way to animals, plants, and the like. Similarly, Nussbaum states that 'inability to laugh is taken, correctly, as a sign of deep disturbance in an individual child (...) an entire society that lacked this ability would seem to us both terribly strange and terribly frightening' (Nussbaum 1990, p. 223). Hence the capability for humor and play should be on the list. And so on for the other capabilities.

To us it seems that this argumentative strategy doesn't succeed. To see why, let's start by imagining a creature that we will call the Humorless Warrior. Apart from other normal human features, two things are peculiar about him: he utterly lacks the capacity for humor, he rarely if ever laughs, nor does he make jokes; he is just a very, very serious fellow. He is also aggressive, he normally does not have the patience to solve conflicts peacefully but fights them out instead; he is predisposed to using physical force against others. We take it that we can recognize these two features as human: seriousness and physical aggression seem to be rather common among us. Nonetheless, the capability to laugh is on Nussbaum's list while the capability to fight is not. What should we think of that? With respect to the omission of aggression, Nussbaum comes close to discussing this when she mentions the capacity for cruelty:

'Not all actual human abilities exert a moral claim, only the ones that have been evaluated from an ethical viewpoint. (The capacity for cruelty, for example, does not figure on the list.) Thus the argument begins from ethical premises and derives ethical conclusions from these alone, not from any further metaphysical premises.' (Nussbaum 2000a, p. 83).

We find this puzzling. A footnote to this sentence refers back to the article in which she developed her view on humanity as the decisive criterion. But if the inquiry into which features are human is the ethical inquiry, then she cannot keep any items from appearing on the list. Once she acknowledges that the items represent 'actual human abilities', then cruelty and physical aggression have just as much reason to be there as any other human ability. 
Thus, our Warrior is justified in complaining that Nussbaum has not given him any reason to reject the feature that makes his life fully human. In general, all the 'dark forces of human nature' that make us engage in morally bad actions should be on the list, for they are part of our human nature. If we want to avoid that conclusion, then it seems that humanity cannot do the ethical work Nussbaum wants it to do. It begs the question: which human features require moral protection and why? ${ }^{4}$

The second particular feature of our Humorless Warrior illustrates a different point. The Warrior might complain about the appearance that humor makes on the list, because that capability is utterly worthless to him. Here Nussbaum might reply that many other people like to laugh, and that, moreover, the Warrior is not required to laugh; after all, the state only guarantees the capability, without imposing its functioning. Nonetheless, the Warrior could argue that he has to live in the political community which does levy its taxes and execute its policies on the basis of the list of central capabilities. The fact that it is on the list means that the political community values the capability to laugh as part of a theory of the good; the Warrior rightly feels that this does not represent his views. Moreover, as Nussbaum explains, there is some measure of coercion involved at least in childhood. If the community follows the capability theory, the Warrior will be subjected to training aimed at developing the capability to laugh (Nussbaum 2000a, p. 89ff.). Similar arguments can be made about other capabilities. For example, what to think about state action aimed at ensuring citizens' 'opportunities for sexual satisfaction' (which is part of the capability of bodily integrity). As one critic disapprovingly noticed: 'even if I myself consider sex to be sinful, I am required to fund somebody else's Viagra.' (Nelson 2008, p. 100).

The features of humor and aggressiveness show two distinct but related problems with Nussbaum's attempt to derive political entitlements from observations about human nature. Generally, her theory establishes political entitlements by showing that certain human features are morally worthy of protection. We may agree with her that political entitlements should be based on anthropological-cum-moral judgments. But Nussbaum's criterion of humanity tends to conflate the anthropological, moral, and political judgments. On the one hand, some features which are recognizably human (all too human...) should not be considered morally worthy of protection, and hence a fortiori should not form the object of political entitlements. The example of aggressiveness and other morally bad capabilities generally belong to this category. Some other recognizably human features, even if they are not morally problematic (bad or immoral), aren't morally required either. We may say that they are morally neutral or 'merely permissible but not required'. As a consequence, they do not deserve political protection.

In light of these problems, we propose that a double selection needs to be made. First, some human features deserve recognition at the moral level. The set of morally required and permissible capabilities is a subset of all recognizably human capabilities. Second, some but not all of these capabilities deserve political protection. Merely morally permissible capabilities are generally not weighty enough, and even some morally required capabilities may be excluded from the political domain. We are not saying here how and when judgments

\footnotetext{
${ }^{4}$ Nussbaum thinks that humanity does real work since she uses it to argue against Aristotle's conclusion that women and slaves are excluded from being full citizens. This is correct. What this means is that humanity is fit to select the ethical community that the capability approach is to be applied to. This, however, does not mean that the concept is also fit to select the capabilities that the members of the same ethical community, once constituted, should be entitled to (Nussbaum 1995). There is also the question of how Nussbaum's more recent addition of a 'principle of moral restraint' succeeds in remedying this problem. (Nussbaum 2000a, p. 275). See also (Crocker 2008, p. 189).
} 
about human nature generate moral obligations, and when such obligations should be seen as a suitable basis for political obligation. We are merely pointing to the fact that these are problems that remain unanswered in Nussbaum's theory. Why does the fact that human beings often (if not always) think, have emotions, have contact with other species, play, etc. generate a moral right to do so? Nussbaum remains silent on this matter. She repeatedly insists that she sees her investigation of humanity's essential features as 'ethical' and 'evaluative' (Nussbaum 2006, pp. 162-3, 166, 181, 366). However, it remains unclear why this generates entitlements on the part of those who are human, and obligations on the part of other humans to respect these entitlements. 'Humanity' is insufficiently discriminative to serve as the guiding principle for selecting a capabilities list that deserves political protection.

We would like to emphasize here that Nussbaum develops a conception of 'justice', a political theory with clear reference to the Rawlsian tradition. Nevertheless, her political theory is based on an ethical approach. This remains the case even in her more recent work. For example, the new claim in Frontiers of Justice that we have duties with regard to animals is justified with reference to the 'moral standing' of animals (Nussbaum 2006, p. 362). But if we base political entitlements on moral claims, then we claim moral authority for these claims. For this claim to moral authority we need a justification.

\section{The Justification of Capabilities}

The content of Nussbaum's theory is of course related to her method of justification. How does she justify the judgments she makes about the essential characteristics of a human being? Here we have to follow the distinction between Nussbaum's earlier and her later work, which she herself has repeatedly drawn attention to. Roughly, the difference is that the earlier Nussbaum relied on what she called a 'self-validating' strategy of argumentation, whereas the later Nussbaum conceives of her theory as justified by an overlapping consensus taken from Rawlsian political liberalism. While nowadays most attention is paid to the later Nussbaum, in this section we focus on the self-validating argument.

In her earlier papers Nussbaum started from judgments about human nature that figure in myths and stories. Obviously their occurrence in Homer or Euripides is not itself a sign that they are justified. Rather, the justification arises from a reflection on these stories. We evaluate what it is to be human by testing whether or not we would agree with the judgments in these stories. Nussbaum calls this the method of "internalist essentialism". 5 She contrasts this with 'externalist essentialism', which wants to validate these judgments by reference to facts that are external to us and can be validated scientifically. The battleground between these two forms of essentialism is the interpretation of Aristotle himself. Nussbaum argues against those like Bernard Williams and Alasdair MacIntyre, who have interpreted Aristotle as using a metaphysical biology to justify his virtue ethics. Aristotle would appeal to external facts that can be found in human nature, the kind of facts that science could reveal. Nussbaum maintains that this is the wrong interpretation of Aristotle. According to her, Aristotle is justifying his

\footnotetext{
${ }^{5}$ More recently she admits that this involves testing our beliefs against our intuitions; she would then be engaged in a search for 'reflective equilibrium'. See (Nussbaum 2000a, pp. 101-103, 150). Similarly: '(...) we can agree that the capabilities approach does indeed rely on intuition.' (Nussbaum 2006, p. 83).
} 
ethical judgments by evaluating whether we would want to reject the common beliefs from which we derive them. ${ }^{6}$ As she says:

'for Aristotle, as texts clearly show, the question as to whether a certain function is or is not part of our human nature is a certain special sort of evaluative question, namely, a question about whether that function is so important that a creature who lacked it would not be judged to be properly human at all. This question is answered like any other Aristotelian ethical question: namely, by looking at the evaluative beliefs of the many and the wise.' (Nussbaum 1988, p. 177).

An external foundation, according to her, is unnecessary and undesirable:

'Human nature cannot, and need not, be validated from the outside, because human nature just is an inside perspective, not a thing at all, but rather the most fundamental and broadly shared experiences of human beings living and reasoning together.' (Nussbaum 1995, p. 121; similarly Nussbaum 1992, p. 208).

To see how this inquiry works, it is instructive to look in more detail at one example that Nussbaum uses: Aristotle's famous statement that man is by nature a political being. This statement is meant to convey that man cannot reach self-sufficiency on his own, but only on the level of the polis. His argument for this claim, according to Nussbaum, rests on several observations. There is the judgment that friendship (philia) is 'most necessary' for life. Nussbaum quotes Aristotle saying that 'without friends nobody would choose to live, even if he had all the other goods.' (Nussbaum 1995, p. 103). Also, Aristotle uses the authority of Homer, arguing that 'the person who is citiless through nature (...) and not through luck is either an inferior creature or greater than a human being: just like the person denounced by Homer as "without fraternal ties, without customs, without a hearth".' (Nussbaum 1995, p. 106). Finally, Aristotle invokes the use of language amongst human beings as an argument for showing that man is by nature a political being. Now a critic might deny these arguments. As Nussbaum says, Aristotle gives no 'knock-down argument' (Nussbaum 1995, p. 104). The only thing he does is ask the critic to consider whether he could seriously disagree. Thus, Nussbaum says about the critic:

'The defender of solitary self-sufficiency is given a challenge: she must either show that our conception of our identity is not what Aristotle says it is - that it does, after all, accommodate Cyclopes and totally non-social anthropomorphs; or she must persuade us that other aims and beliefs require us to revise these deep beliefs about identity; or she must grant that the proper sort of self-sufficiency for us to aim at is Aristotle's sort; or finally she must dissociate herself from the other parties to the argument, announcing that her conception of identity and nature is truly not the same as theirs, and acting, henceforth, accordingly.' (Nussbaum 1995, pp. 108-109)

In other words, if the first two strategies don't work, that is, if the critic cannot convince us; she is left with the choice between giving in to us, or of sticking with her own conception of human identity in solitary isolation. Nussbaum counts upon the fact that the critic will not choose this last strategy. Indeed, she says that the fact that the defender of solitary selfsufficiency engages in ethical argument with others, is already sufficient proof that she has to give up her thesis about solitary self-sufficiency. No challenger can act as if he is not himself a political being; or at least he cannot do so without great cost to himself. The argument

\footnotetext{
${ }^{6}$ See also Putnam, arguing that the capability approach presupposes an entanglement of fact and value (Putnam 2003, 62-63).
} 
about man as political being is therefore self-validating. Nussbaum concludes: 'The argument is claiming that the acceptance of a theoretical position entails a cost that the proponent of the position will be unwilling to pay - for these are beliefs in terms of which he defines himself.' (Nussbaum 1995, p. 110). This method of justification does not just apply to the justification of the claim about man as political being, of course. It can be used for the justification of all capabilities on the list. For example, when discussing practical reason as an essential human function, Nussbaum says that the affirmation of a 'mindless life', that is, a life without using practical reason, ' ... is not ruled out; what is established is the cost of the choice, and how deeply it is at odds with some of our firmest convictions concerning who we are.' (Nussbaum 1995, p. 117). ${ }^{7}$

Some have argued against both Sen's and Nussbaum's version of the capability approach, that in the end it is as subjective as the method of welfarism (utilitarianism) that Sen and Nussbaum often criticize. Why would it be unreliable, these critics ask, to found a political theory on the answers people give when asked about their preferences, while it would make good sense to ground a political theory in their private evaluations about which capabilities the state should guarantee, or in their public deliberations about these capabilities? Aren't citizens in both cases just as prone to problems like adaptive preferences? (Sumner 1996; Dowding 2006). We think there is something to these criticisms. Nussbaum's method, while it escapes the problems associated with positing the existence of an external realm of ethical facts, risks falling prey to the opposite danger of subjectivism in the evaluation of capabilities.

Recall that Nussbaum claimed that anyone objecting to a certain feature that we say is characteristic of humanity was faced with the choice: convince us we are wrong, accept our judgment, or reject it and suffer the costs. The example of the Humorless Warrior in the previous section shows that on certain items on the list, the critic who raised the objections might bite the bullet: he might say that these beliefs about human identity should actually be rejected. And contrary to Aristotle and Nussbaum, we have no reason to think that the costs to that person of doing so are unbearably high. One might be a Humorless Warrior and still lead a recognizably human life. The problem is that we have put too much faith in our procedure by leaving an escape route to the critic; by granting him the possibility to reject our conclusions. Ethical conclusions should not rely on what has to be accepted unless we are willing to incur high costs; rather they should be based on what we need to accept; or, put differently, on what we cannot deny. Hard conclusions do not follow on pain of high costs, but only on pain of self-contradiction. In other words, as we will argue in the second part of this paper, we need a transcendental argument.

Before we continue with that, we first need to say a few words about the later Nussbaum. One may wonder why we leave her later turn to a political liberal justification of her capability theory out of consideration. We have two reasons for this.

First, while the early Nussbaum is rather straightforward, it is much harder to interpret what method - or rather: methods - the later Nussbaum actually uses. We take it that she uses at least three methods simultaneously, without reflecting on their mutual compatibility. ${ }^{8}$ First, given certain references in her footnotes, it seems that she does not discard the (older) self-validating argumentative strategy - although it doesn't appear explicitly in her main text. Second, she now predominantly seems to interpret her ethical judgments about

\footnotetext{
${ }^{7}$ Nussbaum's hope that our judgments on these matters will converge depends (partly) on the fact she believes that we share certain 'grounding experiences'; Aristotelian virtues are the correct attitudes towards these grounding experiences in different spheres of life. See (Nussbaum 1993).

${ }^{8}$ Moreover, she adds narratives and imagination as sources (as part of or besides intuitions?) of moral reflection, and also gives a 'limited and ancillary role' to informed desire (Nussbaum 2000a, p. 152). For a discussion of the relations between these methods of justification in Nussbaum, see (Jaggar 2006).
} 
(dignified) humanity as part of the method of reflective equilibrium. We compare the capabilities approach to other approaches (utilitarianism, contractarianism, etc.) and use our intuitions to test which theory gives the most plausible judgments. (Nussbaum 2000a, pp. 101-102; similarly Nussbaum 2006, p. 5, 389). Indeed, Nussbaum is less and less shy in admitting that intuitions play a foundational role for her theory (Nussbaum 2000a, p. 150, 212; 2006, pp. 83-84, 173-174, 278-279). Third, Nussbaum adds Rawls's political-liberal method of the overlapping consensus (Nussbaum 2000a, p. 74, pp. 102-103; 2006, p. 70, 163,182 , pp. 298-305). The result of all this is a method she refers to as a 'complex holistic method' (Nussbaum 2006, p. 355).

It is difficult to see how these three methods may be reconciled. For example, the method of reflective equilibrium relies on a thought process engaged in by the theorist (philosopher). The equilibrium reached is in the beliefs of the theorist, not in the beliefs of anyone else. The substantive outcome of this method is justified in the sense that the theorist judges it justified after a process of private reasoning that represents the best of his abilities. Others may play a role in this; for example, they may offer objections to the theorist and make him improve his judgments. Nonetheless, their role is confined to delivering input that the theorist processes to come to a better equilibrium. In political liberalism, by contrast, the others play a central role. The overlapping consensus is a public device of justification. The outcome is now justified because it represents a (factual, or hoped for) point of agreement between all (adherents to) comprehensive religious or moral doctrines. This is a completely different method of justification and it is prima facie hard to see how the two may be reconciled. Similar remarks can be made about the relation between these two methods and the earlier method of self-validation.

It is fair to say that within the later Nussbaum, the emphasis is on her political liberalism. This is the characterization she herself uses most frequently. This leads us to a second reason for leaving the later Nussbaum out of consideration: we believe that the method of the overlapping consensus is unsuitable as a way of justifying a capabilities list. The weaknesses of the political liberal strategy have of course been extensively discussed in the context of Rawls's political liberalism. For reasons of space, we simply refer to these criticisms. Suffice it to say that we agree with many critics that the most fundamental problem is that of universal validity. The fact that a theory is supported by an overlapping consensus does not justify its substantive correctness. The overlapping consensus was presented by Rawls in the context of a concern for stability, not for substantive correctness, of his doctrine of justice as fairness. Rawls wants to limit his theory in Political Liberalism to democratic countries with a constitutional regime. Both of these qualifications provide problems for Nussbaum, who aims at a universal theory which is not just stable, but also correct, and potentially applicable world-wide. ${ }^{9}$

The overlapping consensus does not bring Nussbaum a satisfactory foundation for her capabilities approach. In this respect, as we have tried to show, her earlier method of selfvalidation is more promising. This method is one of the places where her theory can be fruitfully connected to and improved by that of Alan Gewirth. But we will now start with our other point of comparison: the substantive normative criterion.

\section{The Necessary Goods for Action}

In his book Reason and Morality (1978), Gewirth defended a supreme moral principle, the Principle of Generic Consistency (PGC) and showed in detail how to apply this principle in

\footnotetext{
${ }^{9}$ For important criticisms of Rawls's political liberalism, see (Raz 1990; Mulhall and Swift 1996). Nussbaum has recently defended her political liberalism in (Nussbaum 2011).
} 
various practical discourses. His approach has been widely discussed with regard to its basic assumptions and the strengths and weaknesses of its justification (Regis Jr 1984; Beyleveld 1991; Steigleder 1999; Boylan 1999), but also applied to discourses about human rights, political philosophy, economy, and bioethics (Gewirth 1982; 1996; 1998; Beyleveld and Brownsword 2001; 2007).

The PGC states: 'Act in accord with the generic rights of your recipients as well as of yourself' (Gewirth 1978, p. 135). These 'generic rights' are specified as rights necessary in order to be a 'prospective agent'. The capacities and preconditions I need in order to act as an agent require protection and support by other agents and political institutions. Where Nussbaum is speaking about 'humanity' Gewirth refers to agency. ${ }^{10}$ Gewirth defines 'agency' in terms of two features, i.e. 'voluntariness' and 'purposiveness'. Gewirth uses a quite basic concept of agency that only assumes that an agent is able to act in a voluntary and goal-directed manner. Now, this is an assumption that is unavoidable insofar as all practical prescriptions (prudential, moral, or political) presuppose this basic capacity. Therefore agency is not an arbitrary but a necessary reference point for normative prescriptions. The basic normative idea of the PGC is that all agents are morally obliged to respect the 'generic rights' of all agents. These generic rights protect the 'generic goods', i.e. those goods that prospective agents need in order to act prospectively; they correspond to Nussbaum's capabilities as the necessary requirements to fulfill central human functions. Gewirth, like Nussbaum, justifies our obligation not with regard to the realization of specific goals or the maximization of wellbeing. Rather, we are obliged to make sure that other agents are enabled to fulfill their purposes in their actions. The generic rights are further specified as rights to 'freedom' and 'well-being' as the two aspects of prospective agency: 'freedom' because it is the distinguishing characteristic of agential behavior and 'well-being' as referring to the general abilities that are required for attaining the purposes of action (Gewirth 1978, pp. 52-62).

The inclusion of 'well-being' in his account of generic rights indicates Gewirth's commitment to a broad scope of moral duties. Gewirth distinguishes between negative and positive rights: while negative rights are rights prohibiting interference in the exercise of our prospective agency, positive rights are rights to being supported in developing our relevant capabilities. Since his normative criterion is to enable prospective agents to realize their basic capacity of autonomous agency, he needs to include both negative rights and positive rights, a standpoint which is similar to Nussbaum's (Gewirth 1996, p. 31, 70). Agents not only have the right not to be interfered with in the exercise of their autonomy, but also the right to receive support for the development of their capacity as prospective agents. These social and welfare rights are, however, only granted to the extent that they are necessary for the realization of our prospective agency.

Gewirth formulates the PGC as one central principle. That allows him to develop a hierarchy of goods that deserve moral protection. If the normative idea is that we should be enabled to act as prospective agents, then the hierarchy follows from the relative necessity of each good for acting as a prospective agent. For the development of this hierarchy he proposes several distinctions. As we have seen, there are duties with regard to the wellbeing and to the freedom of prospective agents. With respect to freedom Gewirth explains that it 'consists not only in exercising control over one's behavior by one's unforced choice

\footnotetext{
${ }^{10}$ Gewirth, like Nussbaum, refers to the concept of human dignity as the basis of human rights, but he explains this concept with regard to 'agency' as the feature that is normatively distinctive for human beings (Gewirth 1992). It is not impossible that there are non-human agents, or that we are at least not sure to what extent animals have agential capacities as well. That could be a reason to grant them some moral status.
} 
in particular situations, but also in having the long-range effective ability to exercise such control.' (Gewirth 1978, p. 249). In general Gewirth sees freedom as a basic good that should only be limited to 'prevent or remedy interferences with other persons' necessary conditions of action' (Gewirth 1978, p. 271). With respect to well-being Gewirth distinguishes three categories of goods: basic, nonsubtractive, and additive goods (Gewirth 1978, pp. 210-248). Basic goods refer to capacities that are so basic that a person would lose his status as an agent if these goods would not be accessible. Those basic goods are his life, basic bodily integrity, health etc. Nonsubstractive goods are goods necessary to maintain an agent's level of 'purpose-fulfillment'. It would harm an agent to be severely reduced in those abilities. Additive goods are goods that an agent needs in order to 'increase his capabilities of purpose-fulfilling action'. Other agents are to some degree obliged to 'respect the additive goods or abilities' of other agents (Gewirth 1978, pp. 240-241).

The relative importance of these goods and the corresponding duties of others are of course dependant on their relative weight in comparison to the concurrent goods of others. This brings us to the problem of hierarchy. To structure rights to well-being and freedom, Gewirth doesn't propose a fixed hierarchy of rights but instead presents some criteria that allow us to determine which capabilities in moral conflicts are more important than others. One of these is the 'degree of necessity for action' (Gewirth 1978, p. 343). On the basis of this criterion, the protection of an agent's freedom and basic well-being takes priority (at least prima facie) over nonsubtractive and additive well-being. In each specific case, there will be debate and disagreement about these criteria. For our purposes here, it suffices to say that potential conflicts have to be solved by the PGC and the ordering of the different categories of goods that this principle dictates. The PGC functions as the organizing principle for determining the scope and the relative importance of the basic capabilities that are forming the basis of rights and entitlements.

Finally, Gewirth's theory distinguishes between direct and indirect applications of the PGC. The same principle that justifies the selection of rights to the exercise of basic capabilities (direct application) is also guiding for the legitimation of political institutions (indirect application) (Gewirth 1978, pp. 272-365). If the enabling of an autonomous life is the general criterion for moral obligations, the obligations of political institutions have to be oriented towards this enablement as well. There is therefore a relative priority for those institutions that are necessary for the protection of the basic freedoms but the principle also justifies the institutions that are necessary for education, social security etc. In that sense it is quite obvious that Gewirth proposes a moral justification for political obligations. In that sense he is more outspoken than Nussbaum, even if Nussbaum herself comes quite close to a conception of politics along similar lines.

This short overview will, of course, raise various questions. Some will concern the application of his principle (demonstrated at great length in Reason and Morality). For our context the important thing is that Gewirth's supreme principle allows us to justify the selection and the relative weight of those capabilities that deserve moral protection. In that sense Gewirth's proposal forms a theoretical alternative to Nussbaum's position that all capabilities are on the same level of normative importance. Gewirth's principle is a supreme principle, comparable to Kant's Categorical Imperative or the Greatest Happiness-Principle in Utilitarianism. Such a principle functions in a fundamentally different way than, e.g., the mid-level-principles we find in contemporary applied ethics, such as the principle of autonomy or the precautionary principle. Such mid-level principles have a more limited heuristic function or a function for just one specific context of action. The structure of a theory using one supreme principle is different. It allows for more concrete rules or principles for particular contexts, but it will always interpret more concrete principles within 
the normative framework of this overarching principle. The concrete normative judgments it delivers will depend, however, not only on the principle and its specifications but also on the morally relevant circumstances of action. If the PGC requires us to protect the necessary preconditions of agency, then the concrete normative content that follows will change depending on the possible threats to this basic normative good. If for example the natural environment changes dramatically, then the list of generic goods of agency can change its content as well. Yet this change is not a result of a change in the normative framework but a change in the specification of the basic normative principle under changing circumstances.

\section{Transcendental Justification: The Dialectically Necessary Method}

So far, we explained only the normative theory proposed by Gewirth. But as was the case with Nussbaum's capabilities theory, we can now ask how Gewirth's theory is able to justify moral authority. When we ask for the justification of a theory, it is not just the general discussion about the sense and non-sense of morality which is at stake (the question 'Why be moral?'), but also a demonstration of why the specific claims made by this approach are valid and legitimate claims. Here it's important to have in mind what the claims of both theories are: Nussbaum offers a theory that shows that we have categorical obligations to respect the capabilities for human beings, while Gewirth claims that his supreme principle can function as the criterion for determining our moral obligations with regard to each other which are specified as the necessary conditions of being a prospective agent. Nussbaum offers two arguments as we have seen: a self-validating argument and-in her later workthe overlapping consensus argument. We have already discussed the problems with both proposals. Gewirth offers as an alternative a kind of transcendental argument.

The idea of a transcendental argument is known since antiquity when the example of the Cretan who says that all Cretan are liars, was often mentioned. In making his statement this Cretan denies the necessary preconditions of making any statement with a truth-claim. His statement is not wrong or false, but it undermines the possibility of making a true statement. The problem is not a problem in the logical, conceptual, or empirical structure of his statement but in the contradiction between the content of his statement and the conditions of being able to formulate a valid proposition in the first place. Transcendental arguments are discussed in various forms and with diverse argumentative goals. Since there is not one definition of what transcendental arguments are, it can be disputed how Gewirth's strategy relates to that of other authors. For our context it is only important to see that Gewirth is developing a strategy in which he wants to demonstrate that an agent has to accept some judgments that, in the end, imply a commitment to the PGC and that the way to demonstrate this is self-reflexive. That means he proceeds by elaborating necessary judgments whose validity we can prove by reflecting on necessary implications of our own agency. To some extent that method is similar to Nussbaum's attempt (see Section 3 above). But Gewirth does not assume that the proof for the validity of the PGC is self-validating. Rather he feels that we have to show in a methodologically transparent way why we would have to be committed to the PGC.

Gewirth calls his method the diallectiacally necessary method. The purpose of this method is to offer a sequence of dialectically necessary judgments. While assertoric judgments are judgments about an object ( $\mathrm{X}$ is green), dialectical judgments are judgment about the person who judges ( $\mathrm{A}$ is of the opinion/believes/fears/hopes that $\mathrm{X}$ is green). Some dialectical judgments are contingent (A believes or does not believe that $\mathrm{x}$ is green) but some of them are dialectically necessary, i.e. the person who makes them cannot deny them 
without denying the necessary requirements of being able to make those judgments. Gewirth uses his dialectically necessary method to demonstrate that there are some judgments an agent cannot deny by virtue of his being an agent. That does not mean that those judgments are true, in the sense that they would refer to an objective or otherwise agent-independent reality. But they are just dialectically necessary for the agent insofar as he is an agent.

Gewirth's aim is to show that the Principle of Generic Consistency, his moral principle, is dialectically necessary. An agent cannot deny this principle without denying that he is himself an agent. To prove this, Gewirth offers a sequence of dialectically necessary judgments. It starts with the statement that each agent has to judge the goals of his action to be good for him. That does not mean that those goals are in an objective sense a good (neither in a prudential nor a moral sense) but only that the agent himself cannot deny that he values them as a good. Once I decide to have it as my goal to see all episodes of Star Trek, then being able to see them becomes valuable for me (even if in a more objective sense it is a waste of time and subjectively I don't feel happy afterwards). But in any case for me as the agent that decides to watch, it is a good to do so.

The second step is that if the agent considers the goal implicit in his action to be positively valuable, then he also needs to consider the necessary means for reaching this goal to be good. This is only true with regard to goals that we actually strive for. Maybe in a mood of wishful thinking we dream of having a lot of money, but the only means that we realistically can imagine to reach that goal are based on criminal activities. That could be a reason for us not to set ourselves on a path of realizing this wish; it never actually becomes an end for us. In any case, with regard to our purposes of action it is dialectically necessary to value the necessary means as goods as well.

In the third step, Gewirth distinguishes between those means that are only necessary for specific goals from other means that are necessary for all our prospective actions. The most basic example would be: whatever goal I want to achieve, I will always have to be alive to reach that goal. Gewirth calls those goals we have to see as necessary means independent from the specific purposes of action: 'generic goods'. Those generic goods are 'freedom' and 'wellbeing' (as conditions of prospective agency, in the sense explained above). Those generic goods are dialectically necessary for the agent independent from the concrete purposes of his action.

The fourth step is that if the agent has to evaluate the generic goods as goods, he must want others-insofar as they have an influence on his opportunities for realizing those goods - to not interfere with his possibility of realizing those goods. This is formulated in terms of an imperative: 'All other persons must at least refrain from interfering with my freedom and well-being' (Gewirth 1978, p. 81). From this imperative, Gewirth takes the crucial fifth step, that the agent then also has to judge that he has a right to those goods-rights protecting him in those cases where others have the possibility to endanger his opportunities for realizing the goods. Denying this right would amount to denying the imperative, and if an agent would do that he would contradict himself (having to want non-interference, but not claiming a right to it).

Finally, for the sixth and last step it is important to remember that all the previous steps are only dialectically necessary by virtue of our agency. If I weren't an agent, these judgments wouldn't be necessary for me. The dialectically necessary judgments mentioned so far are only necessary by virtue of my being an agent. That means they are not contingent thoughts an agent may or may not have. They are dialectically necessary only because they are judgments that I have to accept because I am an agent. If, however, my agency is the only reason why I have to accept those judgments as dialectically necessary, then it is logically necessary for me to think that all agents have the right to the necessary preconditions of 
agency. Therefore we can conclude that all agents have to think that they are obliged to respect the generic rights of all agents, and that is the Principle of Generic Consistency (PGC).

This overview is much too brief to show all the details and discuss criticisms. The relevant point was to show the structure of the argument. Gewirth offers a kind of justification which is neither deductive (deducing the principle from another principle; which would raise the question how to justify this other principle) nor inductive (a generalization from various concrete moral judgments, which would raise the question how I know that these are valid moral judgments) but dialectical. Gewirth doesn't demonstrate that the PGC is true in an agent-independent sense, but only that it has to be accepted by each agent just by virtue of being an agent. The PGC is neither the result of a contract between agents nor the result of a mutually advantageous bargaining process. Rather it is a conclusion we reach by thinking about the necessary implications of our own agency. This insight has the consequence that morality is now based on a necessity we can understand as a result of reflecting on our own agency. The principle not only demonstrates the reason for giving normative force to the basic capabilities, but it also shows the criterion for determining the content of our moral obligations.

\section{Gewirth's Potential Contribution to Capability Theory}

In this section we want to connect both authors and make some suggestions as to how Gewirth's moral theory could help us overcome the problems with Nussbaum's capabilities approach that we have identified earlier. We will briefly discuss three themes which have reappeared several times throughout this paper: the selection of capabilities, the question of hierarchy, and the method of justification.

First, with respect to the selection of capabilities, the key difference is in Nussbaum's use of 'humanity' versus Gewirth's use of 'agency' as the fundamental touchstone of moral reflection. Given the weaknesses of humanity: what would it mean for Nussbaum to incorporate Gewirth's criterion of agency in her theory? A full answer to that question would require another paper. Most generally, Nussbaum has always argued that her capabilities theory is respectful of agency since it only sets capabilities as a political goal. When individuals have a certain capability, they can decide for themselves whether or not to exercise it and function in the corresponding way (Nussbaum 2000a, p. 87). We have argued that this move is in itself not sufficiently respectful of agency if it is accompanied by a very expansive list of capabilities (see the discussion in Section 2 above). This doesn't mean, of course, that we should do away with the distinction between capabilities and functionings. It just means that the distinction should be applied to another list of capabilities.

In this respect Nussbaum argues that two central capabilities have a coordinating role amongst all capabilities: the capability of practical reason and the capability for affiliation. She says that these 'infuse' the way all other capabilities are realized. One could think of removing the capability of practical reason from the list of central capabilities, and assigning it the role of normative criterion that selects capabilities for the list. Only those capabilities necessary to practical reason should figure on the list. Such a move would make it possible to find a non-arbitrary criterion to determine which capabilities deserve universal moral protection. By restricting ourselves to a list of capabilities having a necessary relation to practical reason, we would relieve the state of promoting exotic capabilities like humor, sex, and appropriate relations to other species. We would also have a clear reason to refuse 
support to all too human but still morally problematic capabilities - like the capability to use physical force. This would be roughly in line with the role agency plays in Alan Gewirth's proposal.

If we would follow this transformation, it would of course then be imperative to reevaluate the role of the capability for affiliation. Nussbaum describes this as the ability "to live with and toward others, to recognize and show concern for other human beings, to engage in various forms of social interaction; to be able to imagine the situation of another and to have compassion for that situation; to have the capability for both justice and friendship' (Nussbaum 2000a, p. 79). It is clear that similar concerns enter Gewirth's theory at a different point. They are central to his discussion in The Community of Rights. Here he discusses how all persons have obligations of 'mutuality' and 'reciprocity' towards others (Gewirth 1996, pp. 75-79). Indeed, he claims that the rights he has argued for 'represent an institutionalization of love as a deep concern for the freedom and well-being of all the members of the society' (Gewirth 1996, p. 83). Nonetheless, it remains the case that the social context of action hasn't influenced the formulation of these rights in the first place. In that sense a concern for relations between people has a less fundamental role in Gewirth's theory and taking this over would require Nussbaum to give up the special role affiliation has in her theory.

Second, following Gewirth we could think differently about Nussbaum's refusal to endorse some sort of hierarchy between capabilities. Gewirth, as we discussed above (in Section 4) splits the generic goods of agency into two categories: 'freedom' and 'wellbeing', the latter in turn divided into three types of goods. A similar hierarchy could be made amongst the objects on Nussbaum's (or any other's) list of capabilities. Nussbaum always refused this, stating that the capabilities are 'incommensurable', and that her list is a list of 'separate components' (Nussbaum 2000a, p. 81). According to her, a trade-off which would bring some people below the threshold for some capability would necessarily be tragic. We think that Nussbaum is right in insisting that every capability adds something distinctive, and that for an ideally just society every person should enjoy every central capability at, or beyond, the threshold level. However, in many situations trade-offs need to be made and we believe that more can be said about these situations than that they are tragic in character.

As we saw, Gewirth proposes a criterion of degrees of necessity for agency. The same criterion that serves to select these capabilities can serve to rank them. Not every capability is equally strongly connected to the overarching end-goal of ensuring each person a sufficient level of agency ('life' is more essential than 'play'). Following this line of thought, one could explore the possibilities for bringing some additional structure into the capability list. Gewirth is not unique in approaching the resolution of conflict in this way. In other human rights theories similar moves are made. For example, recently James Griffin proposed that human rights must be understood in terms of the value of agency, then argued that agency consists of three parts (what he calls 'autonomy', 'liberty', and 'minimum provision'), and finally proposed to solve conflicts by looking at the extent to which a course of action under consideration violates agency. As he states: 'There are, I have proposed, rightright conflicts. Virtually everyone would agree that an important part of their resolution comes by determining the degrees of the values constitutive of personhood at stake.' (Griffin 2008 , p. 68). Whether or not Griffin is right in thinking that this is an almost unanimously shared strategy of conflict resolution, it remains mysterious why Nussbaum would have to continue to reject it. In our view, only her fear of full-scale commensurability has withheld her from doing so. But we can honor the status of every single capability as a prima facie demand of justice (as we do with every single human right) and at the 
same time agree that in cases of conflict the theory offers some guidance by way of its central normative criterion.

Third, there are consequences for the method of justification. Following Gewirth would mean to reject Nussbaum's later attempts to ground her capability theory in some form of political liberalism, and make us go back to her earlier, more Aristotelian 'self-validating' method of justification (see Section 3). To start with, it is interesting to note that Nussbaum expressed her sympathy for the type of transcendental argument that Gewirth and others have put forward:

"[i]n certain specific argumentative contexts, we may point out that our interlocutor's very behavior shows that she grants the centrality of the element on whose centrality we are insisting. There would thus be a pragmatic self-contradiction were she to reply by denying its importance. Thus, it would be self-contradictory to engage in philosophical argument about the ends of human life and then deny that reason and argument have any importance. It would be similarly peculiar to attend the dramatic festivals of Athens looking for illumination about matters of human significance and then to deny that community with others has any importance at all. I find these patterns of argument interesting, and I think that they can sometimes do real work in convincing a certain type of opponent, but I do not rely on them." (Nussbaum 2000b, p. 122).

Unfortunately, she hasn't expressed herself more extensively on this topic. After having introduced Gewirth's transcendental method of justification (see Section 5) we are now in a position to see that Nussbaum's self-validating strategy of justification is a close cousin of Gewirth's transcendental argument. To draw this out systematically, we can say that both methods share three key points.

First, they both start from an internal perspective: that of a human being (Nussbaum) or an agent (Gewirth). There is no attempt at a so-called realist justification of moral conclusions. Second, they both work dialectically. In Nussbaum, we are asked to imagine a dialogue between a proponent of the theory and a moral skeptic, who are both assumed to share the internal standpoint of humanity. For Gewirth, the dialectic as it is presented remains internal to the agent who is deliberating ('with himself', so to speak) about the normative presuppositions of action. But here too the purpose is to defeat the skeptic who would want to deny certain steps in the argument (Gewirth 1978, p. 7, 354). Third, both methods work by identifying propositions that such a skeptic must take into account, while he cannot do so if he wants to remain faithful to the standpoint he is talking from. Both methods try to make an incoherence explicit that exists between what one $i$ s and what one commits oneself to when uttering certain statements.

It is at this last point that Nussbaum and Gewirth part ways. While she thinks that only those moral conclusions can be established which a skeptic cannot deny on pain of very high costs, Gewirth goes one step further and argues for conclusions which a skeptic could not deny at all. Of course one can try to deny that he has succeeded in establishing the particular conclusions that he aimed for; indeed there has been a lively debate about the validity of every step of Gewirth's transcendental argument (Beyleveld 1991). We will not engage in that debate here. For our purposes, it suffices to conclude that we see no principled reason why Nussbaum could not use the same method in arguing for the specific list of capabilities. The key question to focus on would then become which capabilities agents (or human beings) need to function as agents (or human beings). Much more could be said about how this should be worked out, but we hope that at this point enough has been said to show both the closeness of Nussbaum's and Gewirth's theories and the opportunities for enriching the former with elements of the latter. 


\section{Conclusion}

We hope to have shown that Gewirth offers a promising strategy that should be discussed within the debate about the capabilities theory in order to broaden the scope of theoretical alternatives. But even if one disagrees about the merits of Gewirth's argument, we hope our comparison has a methodological importance of its own.

It was also our ambition to broaden the scope of the debate and formulate questions any capability theory has to answer. First, is the aim of a theory just to show that we all agree on the value of certain capabilities or does such a theory want to show that we ought to protect those capabilities? (The question of normative force.) Second, which capabilities are so fundamental that they deserve protection and support? (The question of selection.) Third, are all of them important to the same degree or is there a possibility to determine the relative weight of the capabilities in the form of a hierarchy? (The question of relative weight.) Fourth, what kind of strategy is adequate to justify the claim that we have a moral obligation with regard to human capabilities? (The question of justification.) Each theoretical proposal can be evaluated with respect to the plausibility of the way these four elements are integrated. If one wants to establish strong normative claims, the form of justification should be appropriate for this aim. If the claim is that we have moral obligations to support animals in their ability to live a life with only a minimum of pain, than it is implausible to justify this claim via reference to an overlapping consensus because it is not obvious that this consensus exists. And it is equally implausible to claim a strong moral and political obligation of states with regard to human capabilities if the selection of capabilities cannot be justified by a normative criterion.

But furthermore it is important to assess the relative strength of any theoretical proposal in the context of the available alternatives. So far, with regard to the capabilities approach to justice the discussion has been confined to Aristotelian and Rawlsian frameworks. That leaves important meta-ethical questions undisputed and raises the question whether there are no theoretical perspectives in the Kantian tradition that might be of interest. Nussbaum tends to make universalistic claims that can perhaps more plausibly be reconstructed with a Kantian concept of categorical moral claims for which self-reflexive arguments in the sense described here, seem to be a promising form of justification. The potential of this strategy would at least deserve to be a topic for serious debate. In that sense, we made a proposal to broaden the scope of debate within the capabilities approach and hope at least to contribute to the clarification of the agenda of the philosophical debate for the years to come.

Acknowledgments Earlier versions of the text were presented at the Annual Dutch Conference for Practical Philosophy (2009) and the Human Development and Capabilities Association Conference (2011). We thank the participants for their questions and suggestions. We also would like to thank the two anonymous referees of this journal for their useful comments.

Open Access This article is distributed under the terms of the Creative Commons Attribution License which permits any use, distribution, and reproduction in any medium, provided the original author(s) and the source are credited.

\section{References}

Beyleveld D (1991) The dialectical necessity of morality. An analysis and defence of Alan Gewirth's argument to the principle of generic consistency. The University of Chicago Press, Chicago

Beyleveld D, Brownsword R (2001) Human dignity in bioethics and biolaw. Oxford University Press, Oxford Beyleveld D, Brownsword R (2007) Consent in the law. Hart Publishing, Oxford 
Boylan M (ed) (1999) Gewirth. Critical essays on action, rationality and community. Rowman and Littlefield, Lanham

Crocker D (2008) Ethics of global development. Agency, capability, and deliberative democracy. Cambridge University Press, Cambridge

Dowding K (2006) Can capabilities reconcile freedom and equality? J Polit Philos 14(3):323-336

Gewirth A (1978) Reason and morality. The University of Chicago Press, Chicago

Gewirth A (1982) Human rights. Essays on justification and application. The University of Chicago Press, Chicago

Gewirth A (1992) Human dignity as the basis of rights. In: Meyer M, Parent W (eds) The constitution of rights. Human dignity and American values. Cornell University Press, Ithaca

Gewirth A (1996) The community of rights. The University of Chicago Press, Chicago

Gewirth A (1998) Self-fulfillment. Princeton University Press, Princeton

Griffin J (2008) On human rights. Oxford University Press, Oxford

Jaggar A (2006) Reasoning about well-being: Nussbaum's methods of justifying the capabilities. J Polit Philos 14(3):301-322

Mulhall S, Swift A (1996) Liberals and communitarians, 2nd edn. Blackwell Publishing, Oxford

Nelson E (2008) From primary goods to capabilities: distributive justice and the problem of neutrality. Polit Theor 36(1):93-122

Nussbaum M (1988) Nature, function, and capability: Aristotle on political distribution. Oxford Studies in Ancient Philosophy, Supplementary Volume I:145-184

Nussbaum M (1990) Aristotelian social democracy. In: Douglas B, Mara G, Richardson H (eds) Liberalism and the good. Routledge, New York

Nussbaum M (1992) Human functioning and social justice: in defence of aristotelian essentialism. Polit Theor 20(2):202-246

Nussbaum M (1993) Non-relative virtues: an aristotelian approach. In: Nussbaum M, Sen A (eds) The quality of life. Clarendon, Oxford

Nussbaum M (1995) Aristotle on human nature and the foundation of ethics. In: Altham J, World R (eds) Mind and ethics: essays on the ethical philosophy of bernard williams. Cambridge University Press, Cambridge

Nussbaum M (2000a) Women and human development. The capabilities approach. Cambridge University Press, Cambridge

Nussbaum M (2000b) Aristotle, politics, and human capabilities: a response to Antony, Arneson, Charlesworth, and Mulgan. Ethics 111:102-140

Nussbaum M (2006) Frontiers of justice. The Belknap Press, Cambridge (MA)

Nussbaum M (2008) Human dignity and political entitlements. In: Human dignity and bioethics. Essays commissioned by the president's council on bioethics. Washington D.C.

Nussbaum M (2011) Perfectionist liberalism and political liberalism. Philos Publ Aff 39(1):3-45

Putnam H (2003) For ethics and economics without the dichotomies. Rev Polit Econ 15(3):395-412

Raz J (1990) Facing diversity: the case of epistemic abstinence. Philos Publ Aff 19(1):3-46

Regis E Jr (ed) (1984) Gewirth's ethical rationalism. Critical essays with a reply by Alan Gewirth. The University of Chicago Press, Chicago

Steigleder K (1999) Grundlegung der normativen ethik. Der ansatz von Gewirth. Karl Alber Verlag, Freiburg/München

Sumner L (1996) Welfare, happiness \& ethics. Oxford University Press, Oxford 